\title{
REVIEW
}

\section{Challenges, concerns and common problems: physiological consequences of spinal cord injury and microgravity}

\author{
JM Scott $^{1}$, DER Warburton ${ }^{1,2,3}$, D Williams $^{4}, \mathrm{~S}_{\text {Whelan }}^{4}$ and A Krassioukov ${ }^{3,4,5,6}$ \\ ${ }^{1}$ Cardiovascular Physiology and Rehabilitation Laboratory, Department of Education, University of British Columbia, Vancouver, \\ British Columbia, Canada; ${ }^{2}$ Faculty of Experimental Medicine, Department of Medicine, University of British Columbia, Vancouver, \\ British Columbia, Canada; ${ }^{3}$ International Collaboration on Repair Discoveries, Vancouver, British Columbia, Canada; ${ }^{4}$ Department \\ of Surgery, McMaster University, Hamilton, Ontario, Canada; ${ }^{5}$ Faculty of Physical Medicine and Rehabilitation, Department of \\ Medicine, University of British Columbia, Vancouver, British Columbia, Canada and ${ }^{6}$ Spinal Cord Program, GF Strong Rehabilitation \\ Centre, Vancouver Coastal Health, Vancouver, British Columbia, Canada
}

\begin{abstract}
Introduction: Similarities between the clinical presentation of individuals living with spinal cord injury $(\mathrm{SCl})$ and astronauts are remarkable, and may be of great interest to clinicians and scientists alike.

Objectives: The primary purpose of this review is to outline the manner in which cardiovascular, musculoskeletal, renal, immune and sensory motor systems are affected by microgravity and $\mathrm{SCl}$.

Methods: A comprehensive review of the literature was conducted (using PubMed) to evaluate the hallmark symptoms seen after spaceflight and $\mathrm{SCl}$. This literature was then examined critically to determine symptoms common to both populations.

Results: Both $\mathrm{SCl}$ and prolonged microgravity exposure are associated with marked deteriorations in various physiological functions. Atrophy in muscle and bone, cardiovascular disturbances, and alterations in renal, immune and sensory motor systems are conditions commonly observed not only in individuals with $\mathrm{SCl}$, but also in those who experience prolonged gravity unloading.

Conclusion: The preponderance of data indicates that similar physiological changes occur in both $\mathrm{SCl}$ and prolonged space flight. These findings have important implications for future research in $\mathrm{SCl}$ and prolonged space flight.

Spinal Cord (2011) 49, 4-16; doi:10.1038/sc.2010.53; published online 25 May 2010
\end{abstract}

Keywords: SCl; spaceflight; muscle atrophy; orthostatic hypotension

\section{Introduction}

Two notable achievements of the latter half of the twentieth century were human space travel and advancements in patient care following spinal cord injury (SCI). Both SCI and prolonged microgravity exposure are associated with marked deteriorations in various physiological functions. Atrophy in muscle and bone, cardiovascular disturbances and an unbalanced immune response are other conditions commonly observed not only in individuals with SCI, but also in those who have traveled in space for prolonged periods (Table 1). These similarities make it feasible for microgravityinduced degeneration to provide an excellent experimental model for investigation of long-term deconditioning on Earth. Likewise, research examining how to improve the physiological consequences of SCI could be applied for the treatment of maladaptations that occur during prolonged spaceflight. Accordingly, to highlight common physiological

Correspondence: Dr JM Scott, Exercise Physiology and Countermeasures, NASA Johnson Space Center, 2101 NASA Parkway, Houston, TX 77058, USA. E-mail: jessica.m.scott@nasa.gov

Received 13 October 2009; revised 10 April 2010; accepted 13 April 2010; published online 25 May 2010 consequences of microgravity and SCI, this review will describe how cardiovascular, musculoskeletal, immune, renal and sensory motor systems are affected by each condition. As this review deals primarily with long-term ( $>24 \mathrm{~h}$ ) adaptations to SCI and microgravity; the reader is referred to other reviews ${ }^{1-3}$ for more detailed information outlining acute acclimation $(<24 \mathrm{~h})$ and the time course of acclimation following these conditions. We hypothesized that microgravity and SCI would result in similar pathophysiological adaptations. Furthermore, we hypothesized that the study of SCI on earth provides a good model to evaluate the effects of prolonged spaceflight (and vice versa).

\section{Alterations in the cardiovascular system}

Recognition and management of cardiovascular dysfunction following SCI and microgravity represent challenging clinical issues. Diminished gravitational fluid distribution in astronauts and a lack of descending nervous control to the cardiovascular system in individuals with SCI result in physiological alterations in several areas including orthostatic tolerance, ventricular mass and function, vascular 
Table 1 Comparison of physiological changes following spaceflight and $\mathrm{SCl}^{15}$

\begin{tabular}{|c|c|c|}
\hline & $\mathrm{SCl}$ & Spaceflight \\
\hline \multicolumn{3}{|l|}{ Cardiovascular } \\
\hline \multirow[t]{5}{*}{ Orthostatic tolerance } & $\downarrow$ Tolerance ${ }^{5}$ & $\downarrow$ Tolerance $^{9}$ \\
\hline & $\downarrow$ Sympathetic nervous system activity ${ }^{26}$ & $\downarrow^{29} ; \leftrightarrow^{18} ; \uparrow^{30}$ sympathetic nervous system activity \\
\hline & $\downarrow$ Baroreflex response $^{5}$ & $\downarrow$ Baroreflex response ${ }^{28}$ \\
\hline & $\uparrow$ Antidiuretic hormones $^{5}$ & $\uparrow$ Antidiuretic hormones $^{16}$ \\
\hline & $\downarrow$ Plasma volume ${ }^{34}$ & $\downarrow$ Plasma volume ${ }^{16}$ \\
\hline Ventricular atrophy and dysrhythmias & $\downarrow$ Cardiac muscle mass ${ }^{37}$ & $\downarrow$ Cardiac muscle mass ${ }^{39}$ \\
\hline \multirow[t]{2}{*}{ Vascular dysfunction } & $\uparrow$ Arrhythmias $^{37}$ & $\uparrow^{47}$ or $\leftrightarrow^{48}$ arrhythmias \\
\hline & $\uparrow$ Flow-mediated dilatation $^{61}$ & $\downarrow$ Flow-mediated dilatation ${ }^{58}$ \\
\hline \multirow[t]{3}{*}{ Lipid disorders } & $\uparrow$ Low-density lipoproteins $^{61}$ & $\uparrow$ Low-density lipoproteins $^{68}$ \\
\hline & $\uparrow$ Total cholesterol $^{61}$ & $\uparrow$ Total cholesterol ${ }^{68}$ \\
\hline & $\downarrow$ High-density lipoproteins ${ }^{61}$ & $\downarrow$ High-density lipoproteins ${ }^{68}$ \\
\hline \multicolumn{3}{|l|}{ Musculoskeletal } \\
\hline \multirow[t]{4}{*}{ Muscle atrophy } & Denervation and disuse atrophy ${ }^{81,82}$ & Disuse atrophy ${ }^{73}$ \\
\hline & $\downarrow$ Extensor muscle function ${ }^{69}$ & $\downarrow$ Extensor muscle function ${ }^{73}$ \\
\hline & $\downarrow$ Cross sectional area ${ }^{72}$ & $\downarrow$ Cross-sectional area $^{77}$ \\
\hline & $\uparrow$ Fast twitch ${ }^{85}$ & $\uparrow$ Fast twitch ${ }^{73}$ \\
\hline \multirow[t]{4}{*}{ Bone loss } & $\downarrow$ Bone mineral density ${ }^{88}$ & $\downarrow$ Bone mineral density ${ }^{76}$ \\
\hline & $\leftrightarrow$ or $\uparrow$ Bone formation markers ${ }^{88}$ & $\leftrightarrow$ Bone formation markers ${ }^{76}$ \\
\hline & $\uparrow$ Bone resorption markers $^{102}$ & $\uparrow$ Bone resorption markers $^{76}$ \\
\hline & $\uparrow$ Fracture risk $^{91,92}$ & Likely $\uparrow$ facture risk during prolonged missions ${ }^{76}$ \\
\hline \multicolumn{3}{|l|}{ Other systems } \\
\hline Neurovestibular and sensory motor dysfunction & $\downarrow$ Motor function ${ }^{103}$ & $\downarrow$ Motor function $^{105}$ \\
\hline \multirow[t]{3}{*}{ Renal stones } & $\downarrow$ Sensory function ${ }^{118}$ & $\downarrow$ Sensory function ${ }^{104}$ \\
\hline & $\uparrow$ Risk of stone formation ${ }^{108}$ & $\uparrow$ Risk of stone formation ${ }^{111}$ \\
\hline & $\uparrow$ Hypercalciuria $^{108}$ & $\uparrow$ Hypercalciuria ${ }^{111}$ \\
\hline \multirow[t]{2}{*}{ Immune dysfunction } & $\uparrow$ Urinary tract infection ${ }^{116}$ & $\downarrow$ Immune responsiveness ${ }^{120}$ \\
\hline & $\downarrow$ Immune responsiveness $^{115}$ & \\
\hline
\end{tabular}

Abbreviation: $\mathrm{SCl}$, spinal cord injury.

Note: Example references are provided.

function, and serum lipid levels. Although the symptoms and clinical presentation of cardiovascular dysfunction are very similar, underlying mechanisms and natural recovery/progression differ greatly between individuals with SCI and astronauts.

\section{Orthostatic intolerance}

Orthostatic hypotension is a condition that is commonly documented in astronauts following the return to gravity environment ${ }^{4}$ and in individuals with SCI. ${ }^{5}$ Symptoms in both astronauts and individuals with SCI are very similar, and vary from light-headedness and dizziness to episodes of syncope. ${ }^{6}$ Chronic exposure to micro-activity during prolonged spaceflight, extended bed rest (a model of microgravity) or inactivity experienced by individuals with SCI result in adaptive changes, which in turn lead to severe disabling orthostatic hypotension in returning astronauts and clinical volunteers.

On postural change or following prolonged periods of sitting, patients with SCI frequently experience sudden and rapid reductions in blood pressure often leading to dizziness, light-headedness and/or syncopal events. ${ }^{7}$ Orthostatic maneuver performed during rehabilitation are furthermore reported to induce a decrease in blood pressure, which is diagnostic of orthostatic hypotension in $74 \%$ of patients with SCI. ${ }^{8}$ As a result, this condition often affects an individual's ability to participate in rehabilitation programs and delays rehabilitation. ${ }^{8}$ Orthostatic intolerance has also been reported to occur in up to $30 \%$ of astronauts returning from short space shuttle flights of 4-10 days. ${ }^{9,10}$ In longerduration flights, the prevalence is even greater, with up to $80 \%$ of astronauts experiencing orthostatic intolerance. ${ }^{4}$ The extent to which SCI patients and returning astronauts are prone to orthostatic hypotension can be seen in Figure 1. The left side shows changes in blood pressure and heart rate following passive movement from a supine to seated position in a subject with SCI (C5 ASIA B; (Figure 1b)) in comparison to a healthy control volunteer (Figure 1a). On the assumption of a passive seated position, the SCI subject exhibited a marked, progressive decrease in blood pressures and relative postural tachycardia. In contrast, in the control subject, blood pressures were increased following the change in posture with little change in heart rate. The right side compares postflight changes in astronauts during standing in finishers (white bars) and nonfinishers (black bars) of a 10min stand test. Nonfinishers showed a tendency toward a greater percent increase in heart rate, whereas finishers showed blood pressure increase to a significantly greater extent during postflight standing compared with nonfinishers. ${ }^{11}$ It is interesting to note similarities in heart rate and blood pressure responses between SCI subject (left) and nonfinishers (black bars; right).

\section{Mechanisms of orthostatic intolerance}

SCI results in major alterations in activity of the sympathetic nervous system. Indeed, in tetraplegic individuals there is a virtual absence of spontaneous activity compared with 
a

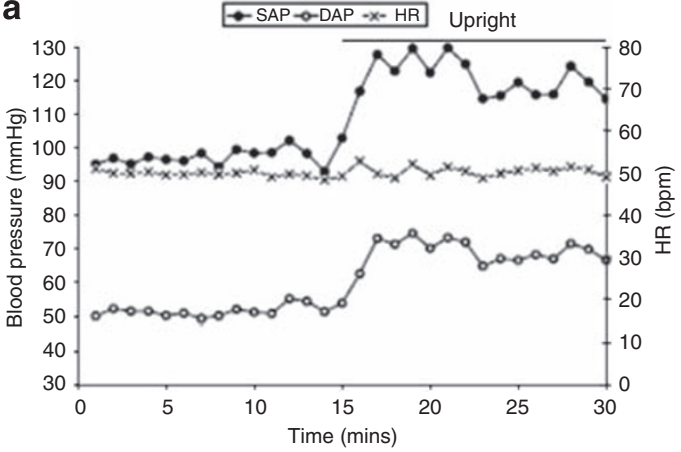

b

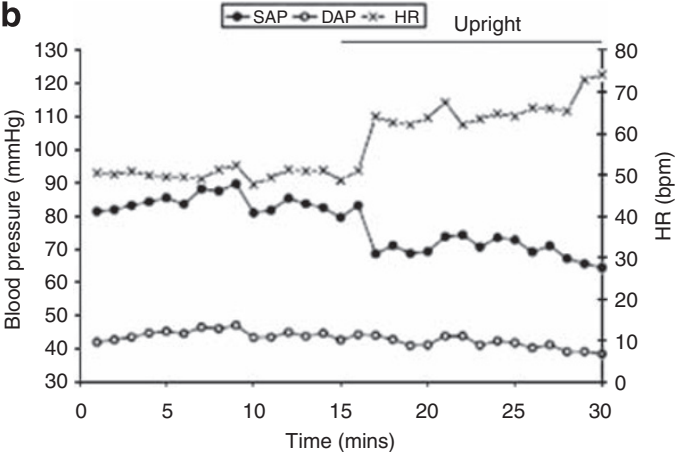

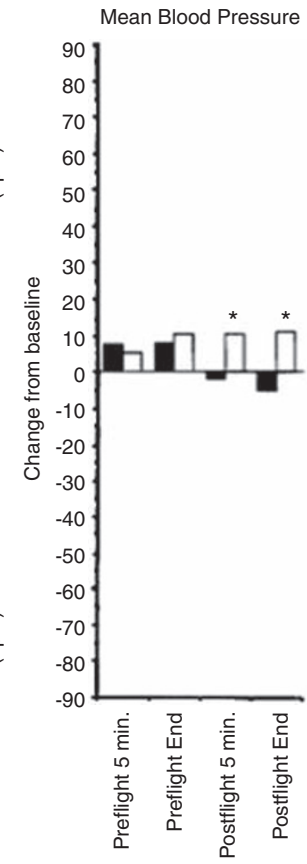

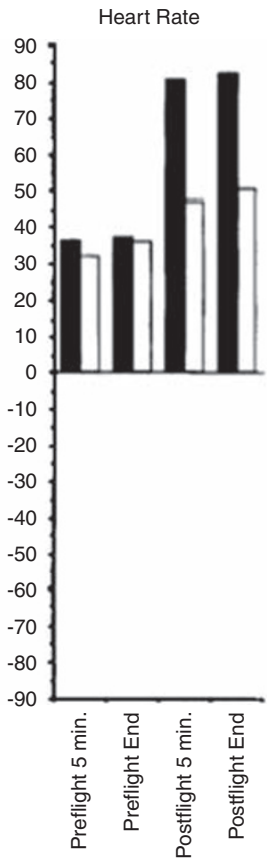

Figure 1 Left: Blood pressure and heart rate responses to orthostatic stress in a healthy male control subject (a) and a man with chronic cervical $\mathrm{SCl}$ ( C5 AIS B; b). The SCl subject had complete destruction of descending autonomic pathways as assessed by the absence of sympathetic skin responses. Resting systolic (SAP) and diastolic (DAP) arterial pressures were higher in the control than the SCI patient. Resting heart rates (HR) were similar. ${ }^{5}$ Right: Comparison of changes during standing in finishers (white bars) and nonfinishers (black bars) of a 10-min stand test in astronauts. Nonfinishers showed a tendency toward a greater percent increase in heart rate. Finishers showed an increase in blood pressure to a significantly greater extent during postflight standing compared with nonfinishers. ${ }^{*} P<0.05$ for finishers versus nonfinishers. ${ }^{9}$ Note the similarities in HR and blood pressure responses between $\mathrm{SCl}$ subject (left) and nonfinishers (black bars; right). (Figures reprinted with permission).

normal subjects. ${ }^{11}$ Although parasympathetic control is usually preserved in SCI, the synergistic relationship between parasympathetic and sympathetic control is often lost. $^{12}$ The extent to which this disrupts autonomic control is directly related to the level at which SCI occurred. ${ }^{12}$ In general, resting sympathetic tone in animals and humans with SCI is very low. ${ }^{11}$ This disruption of spinal sympathetic pathways likely affects vascular resistance responses to orthostasis. Several investigations have shown that in individuals with SCI, levels of both adrenaline and noradrenaline are abnormally low while in supine position, ${ }^{12}$ and that catecholamine levels fail to increase in response to an orthostatic challenge. ${ }^{13}$ It has been shown previously that these vascular resistance responses have a crucial role in cardiovascular control during orthostatic stress, ${ }^{14}$ and that any impairment in vascular resistance responses following SCI will predispose to orthostatic intolerance. ${ }^{14}$

Data on sympathetic nervous system function in space are indirect, scarce and contradictory. Plasma noradrenaline levels in space have been reported as decreased, ${ }^{15}$ unchanged $^{16}$ or increased. ${ }^{17}$ Despite these inconsistent results, it has been shown that muscle sympathetic nerve activity, in contrast to SCI, was increased in microgravity, ${ }^{9,18}$ data that are supported by most studies using sympathetic microneurography during simulated microgravity on Earth. ${ }^{19}$ However, postflight results suggest similar sympathetic responses between syncopal astronauts and individuals with SCI. ${ }^{13}$ A comparison of responses in presyncopal and nonsyncopal astronauts during their 10 -min standing tests postflight clearly identified a subnormal increase in plasma norepinephrine in the presyncopal group as the critical difference from preflight data. Furthermore, presyncopal astronauts showed a preflight individual predisposition to being more susceptible to postflight orthostatic intolerance characterized by hypoadrenergic response during standing. $^{20}$ In contrast to maintained parasympathetic activity following SCI, a consistent decrease in the parasympathetic nervous system indicator has been observed following microgravity exposure ${ }^{21}$ and bed rest. ${ }^{22,23}$

Differences between sympathetic nervous system response in patients with SCI (compared with able-bodied individuals) and in astronauts (postflight compared with preflight) can be seen in Figure 2. The top graph illustrates mean voltage neurograms from peroneal skin nerve fascicle in a normal subject and a tetraplegic patient (C6 lesion) at rest. Note frequent sympathetic bursts in the neurogram from the normal subject and only a single reflex burst induced by pressure over the bladder (arrow) in the tetraplegic patient. ${ }^{11}$ The bottom graph shows Valsalva maneuvers performed 72 days before the Neurolab space shuttle mission and on mission day $12 .{ }^{30}$ Note the lack of sympathetic activity in the SCI subject, while there is a greater augmentation of 

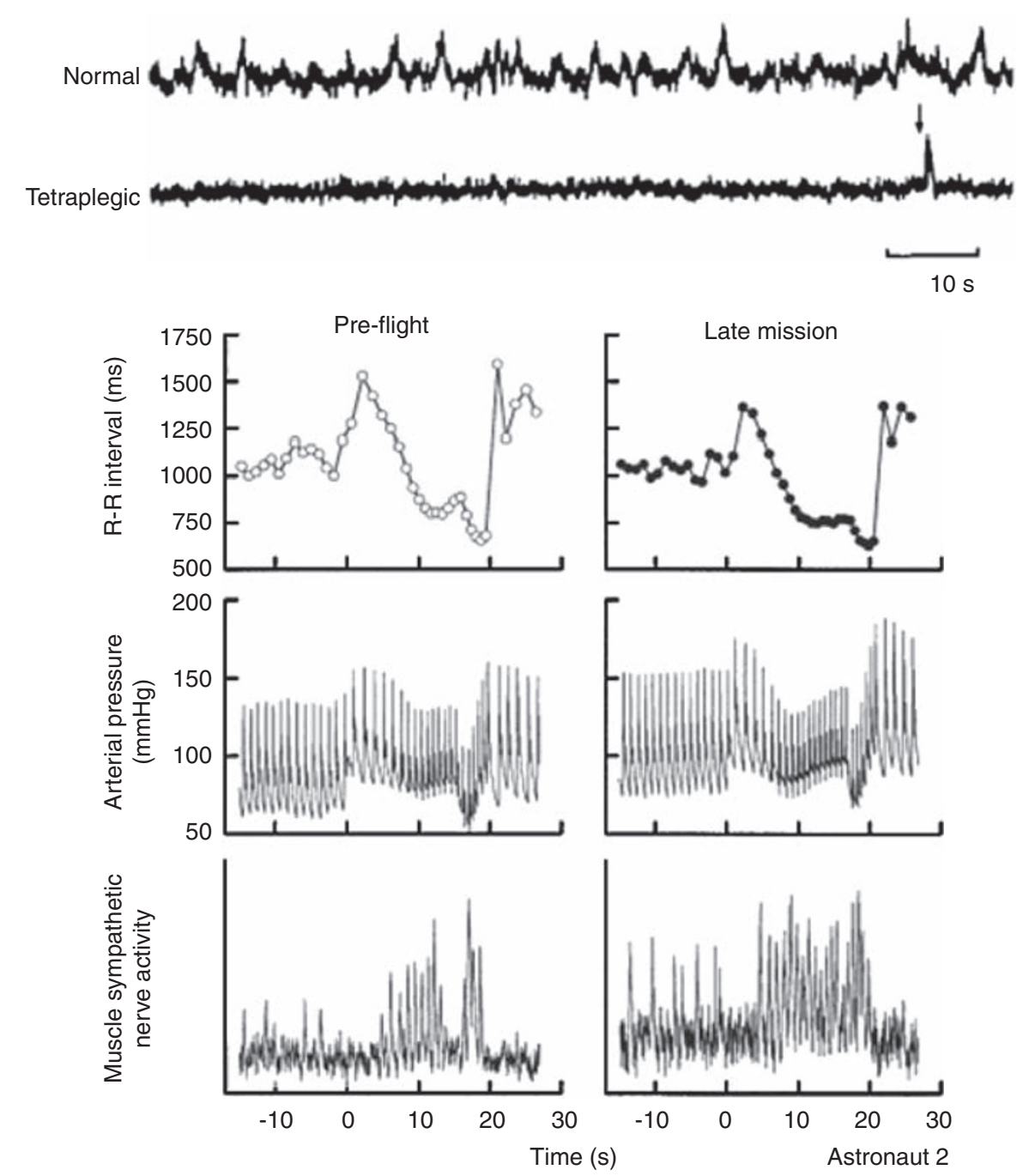

Figure 2 Top: Mean voltage neurograms from peroneal skin nerve fascicle in a normal subject and a tetraplegic patient (C6 lesion) at rest. Note frequent sympathetic bursts in the neurogram from the normal subject and only a single reflex burst induced by pressure over the bladder (arrow) in the tetraplegic patient. ${ }^{11}$ Bottom: Valsalva maneuvers performed 72 days before the Neurolab space shuttle mission and on mission day $12 .{ }^{30}$ Note the lack of sympathetic activity in the $\mathrm{SCl}$ subject, while there is a greater augmentation of muscle sympathetic nerve activity during straining in space than on Earth. (Figures reprinted with permission).

muscle sympathetic nerve activity during straining in space than on Earth.

Altered baroreceptor reflex control may be another factor that contributes to impaired orthostatic tolerance. Baroreceptors are stretch receptors located in the aortic arch, carotid sinus and coronary arteries that respond to perturbations in arterial pressure and reflexively modulate sympathetic and parasympathetic outflow to maintain blood pressure homeostasis. ${ }^{23}$ When assessed using spectral analysis of oscillations in heart rate and blood pressure during orthostatic stress, baroreflex function has been found to be abnormal in patients with SCI with lesions at T3 or above. ${ }^{24}$ Individuals with tetraplegia and paraplegia have also been reported to have impaired baroreflex responses to discrete stimulation of the carotid sinus using neck suction or neck pressure, resulting in reductions in both baroreceptor sensitivity and range of operation. ${ }^{25,26}$ The impairment of baroreflex control in both high- and low-level lesions identified in these studies is another probable factor contributing to orthostatic intolerance in SCI. Indeed, Aslan et $a .^{27}$ examined blood pressure regulation during an orthostatic stress test and found that SCI results in less engagement of feedback control.

There have also been several reports documenting impaired baroreflex responses after Space Shuttle missions. Fritsch et al. ${ }^{28,29}$ examined astronauts with a stepwise neck pressure algorithm and found that the maximum slope and range of the sigmoidal relationship between carotid distending pressures and R-R intervals were significantly less than preflight. Furthermore, the resting position (operational point) of astronauts on this relationship was lower after the space missions than before. ${ }^{30} \mathrm{~A}$ more recent investigation confirmed these findings, showing that the range, maximum gain, and operational point of sigmoid carotid distending 
pressure and $\mathrm{R}-\mathrm{R}$ interval response relationships were all significantly lower in space than on Earth. ${ }^{18}$ The sigmoid relationship between pressure and R-R intervals of heart rate shows a downregulated resetting of the baroreflex response, which becomes apparent even after short (4-5 days) exposure to microgravity. This reduced R-R interval response persists up to 10 days after landing, contributing to orthostatic hypotension. ${ }^{28}$ In summary, altered baroreflex control and the resultant blunted sympathetic response may contribute to orthostatic intolerance both in individuals with paraplegia and in astronauts postflight.

One final mechanism that may contribute to orthostatic intolerance is altered salt and water balance. In able-bodied individuals, orthostatic tolerance and postural blood pressure control are known to be greatly influenced by plasma volume, ${ }^{31}$ whereby larger plasma and/or blood volumes are associated with better tolerance to orthostasis. ${ }^{32}$ In patients with chronic SCI, there is evidence of impaired water and sodium retention, which is confounded by limited salt and water intake. ${ }^{33}$ There is only limited information available on circulating volume following SCI; however, it has also been shown that total blood volume and hemoglobin mass are decreased in individuals with SCI with a lesion above $\mathrm{T} 4 .^{34}$ The combination of increased antidiuretic hormone secretion, low sodium intake, high sodium excretion and resultant hyponatremia are likely to predispose toward lower plasma volumes in patients with SCI. This, in turn, would exacerbate episodes of orthostatic hypotension in these individuals. Furthermore, there is evidence that individuals with SCI respond well to plasma volume increase with use of fludrocortisone, suggesting that plasma volume has an important role in maintaining orthostatic tolerance. $^{35}$

Weightlessness also rapidly alters fluid physiology. Astronauts experience a net volume loss of $\sim 800 \mathrm{ml}$ per day for the first 2 days. ${ }^{16}$ During the first day, adrenocorticotropic hormones and antidiuretic hormones increase markedly and astronauts diminish their fluid and food intake until day 3, when they adapt to space sickness. ${ }^{2,16}$ By the fifth day in microgravity, plasma volume has diminished by up to $20 \%,{ }^{9,36}$ likely contributing to decreased orthostatic tolerance upon return to gravity. 9,36

\section{Ventricular atrophy and dysrhythmias}

Decrease in cardiac mass to levels that are well below normal occur in conditions of weightlessness, bed rest and SCI. In a study that examined changes in cardiac mass and dimensions, de Groot et al. ${ }^{37}$ reported a $25 \%$ decrease in left ventricular (LV) mass in patients with chronic (average 18 years after injury) tetraplegia. Interestingly, in this investigation, there were no reported differences in diastolic or systolic function between individuals with SCI and controls despite significant cardiac atrophy following SCI. de Groot et al. ${ }^{37}$ hypothesized that the LV dimensions, which decrease to maintain wall stress may be an appropriate response to inactivity without compromising cardiac function. Although there are no data to our knowledge that describe the longitudinal decreases in LV mass in SCI, it seems that reduction in mass may be reversible. Nash et al. ${ }^{38}$ described a $35 \%$ increase in LV mass with the introduction of an exercise program using electrical muscle stimulation in individuals with tetraplegia. ${ }^{37}$ These results show the importance of exercise as a countermeasure in maintaining cardiac integrity in individuals with SCI.

Similar to individuals with SCI, astronauts also experience cardiac atrophy. A recent investigation by Perhonen et al. ${ }^{39}$ showed that LV mass measured by magnetic resonance imaging, decreased by $15 \%$ during prolonged supine bed rest in previously sedentary nonathletic men without cardiovascular disease, and decreased by $12 \%$ after short-duration spaceflight. ${ }^{39}$ Although it seems that cardiac atrophy does not affect systolic function as it does in SCI, cardiac atrophy following spaceflight may affect diastolic function. Invasive studies of cardiac performance before and after 2 weeks of head-down-tilt bed rest have shown that there is a leftward shift in the diastolic pressure-volume curve after bed rest, resulting in a smaller LV end-diastolic volume for any given filling pressure. ${ }^{40}$ Given that SCI seems to result in greater decreases in LV mass compared with spaceflight, differences regarding decreases in diastolic function are intriguing. Although de Groot et al. ${ }^{37}$ used echocardiography to assess LV function following SCI, future investigations examining LV performance using cardiac magnetic resonance imaging ${ }^{39}$ or invasive measures ${ }^{40}$ could also reveal decrements in diastolic performance in conjunction with changes in LV mass.

It is well recognized that SCI can provoke altered cardiac electrophysiology and increase susceptibility to cardiac arrhythmias. Sinus bradycardia (a heart rate $<50$ beats per minute) is the most common heart rate abnormality in patients in the acute stage following SCI. However, various other irregularities in cardiac rhythm have been attributed to autonomic instability following SCI, including repolarization changes, atrioventricular blocks, supraventricular tachycardia, ventricular tachycardia and primary cardiac arrest. $^{41,42}$ Development of heart rate abnormalities in patients with SCI is associated with severe injury at the cervical or high-thoracic level. ${ }^{42}$ Furthermore, the most pronounced changes are observed during the acute phase (ranging from 2 to 6 weeks after injury), whereas heart rate parameters can improve substantially in the chronic stage. ${ }^{43,44}$ However, in the chronic stage, physical exertion and sexual activities are most commonly associated with development of arrhythmias. ${ }^{45,46}$

In contrast to SCI, spaceflight does not seem to increase the risk of dysrhythmias. One case study described a single isolated nonsustained, asymptomatic 14-beat ventricular tachycardia episode in a cosmonaut during an extended space mission. ${ }^{47}$ However, subsequent analyses of electrocardiogram tracings of astronauts performing their routine tasks during or following their space missions revealed no greater incidence of cardiac dysrhythmias, ${ }^{48}$ and databases designed to examine electrocardiography tracings obtained from long-duration microgravity exposure have revealed no pathology in the bioelectrical activity of the heart. ${ }^{49}$ It has been proposed that less serious cardiac dysrythmias are events not specifically related to spaceflight, but rather due 
to conditions such as transient myocardial inflammation, electrolyte shifts, heat, pollutants and anxiety. ${ }^{49}$

\section{Vascular dysfunction}

Previous studies have suggested that deconditioning can lead to detrimental vascular changes, such as endothelial dysfunction and atherosclerosis. ${ }^{50}$ Endothelial dysfunction, an initial factor in the development of atherosclerosis, has a significant effect on the long-term risk for cardiovascular disease. ${ }^{51}$ A commonly used noninvasive assessment of arterial function is flow-mediated dilation. ${ }^{52}$ Flow-mediated dilation reflects ability of the endothelium to relax vascular smooth muscle in response to increased blood velocityinduced shear stress. ${ }^{53}$ Reduced flow-mediated dilation is an early marker of atherosclerosis, ${ }^{52}$ a surrogate marker of cardiovascular function, ${ }^{54}$ and a predictor of future cardiovascular complications. ${ }^{55}$

Recent findings suggest that vascular adaptations to inactivity in humans are accomplished within weeks, ${ }^{56}$ not, as was previously thought, over a longer period. ${ }^{57}$ In humans with long-standing SCI, extensive changes occur in the peripheral circulation such as a $30 \%$ decrease in diameter, a reduction in blood flow and an almost doubling of stress levels in the femoral artery. ${ }^{56}$ Interestingly, de Groot et $a l .{ }^{56}$ showed that absolute and relative flow-mediated dilation responses increased significantly during the first 6 weeks of extreme inactivity, with most changes evident at 3 weeks after injury.

Despite considerable research examining endothelial function in various clinical populations, very little information exists with regard to endothelial function of individuals subjected to bed rest or microgravity. In one investigation examining simulated microgravity, Hesse et al. ${ }^{58}$ found that strict bed rest for 13 days impaired endothelium-dependent arterial relaxation in healthy men. Furthermore, Coupe et al. ${ }^{59}$ also showed that prolonged bed rest causes impairment of endothelium-dependent functions at the microcirculation level, along with an increase in circulating endothelial cells. Although ground-based evidence indicates that microgravity may impair endothelial function, this phenomenon has not yet been systematically tested.

\section{Lipid disorders}

Abnormal lipid values have long been established as risk factors for the development of diabetes and heart disease. ${ }^{60}$ After SCI, there is a tendency toward elevated low-density lipoprotein cholesterol and total cholesterol, as well as lower high-density lipoprotein (HDL) cholesterol, levels compared with able-bodied individuals. ${ }^{61}$ Approximately $10 \%$ of the US population has HDL cholesterol values $<35 \mathrm{mg}$ per $100 \mathrm{ml}$, whereas about $24-40 \%$ of those with chronic SCI have levels below this value for HDL cholesterol. ${ }^{62,63}$ In acute SCI, lipid levels are generally depressed and normalize within the first year. ${ }^{64}$ Consequently, previously mentioned alterations in vascular function in individuals with SCI do not seem to be due to elevations in plasma lipids. However, beyond the first year after injury, individuals with SCI tend to develop elevated low-density lipoprotein cholesterol and total cholesterol levels, and continue to maintain lowered HDL cholesterol levels compared with able-bodied populations. ${ }^{65}$ Individuals with tetraplegia tend to have a greater number of lipid abnormalities than their paraplegic counterparts. ${ }^{66}$ This suggests that the metabolic changes and physical inactivity associated with SCI may have significant consequences for the prevalence of dyslipidemia and the development of cardiovascular disease.

Alterations in blood lipids have also been found during exposures to microgravity. This may be a concern for longduration missions, as previous research indicates that the microgravity environment may induce or accelerate the development of risk factors for cardiovascular disease. Significant changes have been reported to occur in concentrations of HDL cholesterol (decreased 8\%) and low-density lipoprotein cholesterol (increased 6\%) compared with preflight values. ${ }^{67}$ Markin et al. ${ }^{68}$ also reported that, as early as the second month of orbital flight, the majority of cosmonauts being tested experienced a significant increase in total cholesterol concentrations (above the normal range). It should, however, be noted that results from the later investigation may be somewhat limited by methodological constraints. Cosmonauts were tested in flight using capillary blood samples taken from a finger with 'Reflotron IV' (Boehringer Mannheim, Mannheim, Germany) biochemical analyzer, a method that may not be as accurate as enzyme immunoassays.

\section{Alterations in the musculoskeletal system}

Maintenance of the musculoskeletal system is of crucial importance to preservation of mobility in patients with SCI and in astronauts in space. Indeed in SCI, performance of simple daily tasks, such as transfers and wheeling depend on the ability of the muscular system to generate sufficient forces to enable displacement of the body. Likewise, in spaceflight, not only does performance of daily tasks, including particularly demanding ones such as extra-vehicular activities, rely on structural and functional integrity of the muscular system, but also the ability to exit rapidly from the space vehicle in case of emergency. Bone health is inherently tied to muscle function, wherein bone loss is likely due to a decrease in mechanical loading as a result of reduced or complete loss of muscle function and/or weightbearing activities. To decrease the risk of fragility fractures that result from bone loss, preserving and maintaining bone mass after SCI and spaceflight are crucial.

\section{Muscle atrophy}

After SCI, there is a rapid and dramatic loss of muscle mass below the level of the lesion. ${ }^{69}$ In individuals who were only 6 weeks after SCI, average muscle cross-sectional areas (CSAs) were $18-46 \%$ lower than in control subjects. ${ }^{69}$ Prospective study of patients up to 24 weeks after SCI revealed further declines in average gastrocnemius and soleus muscle CSAs of 24 and $12 \%$, respectively. ${ }^{69,70}$ Similarly, from 6 weeks to 24 weeks after injury the average decreases in quadriceps, hamstrings and adductor muscle CSAs were 16, 14 and $16 \%$, respectively. ${ }^{71}$ Results from a recent investigation on 

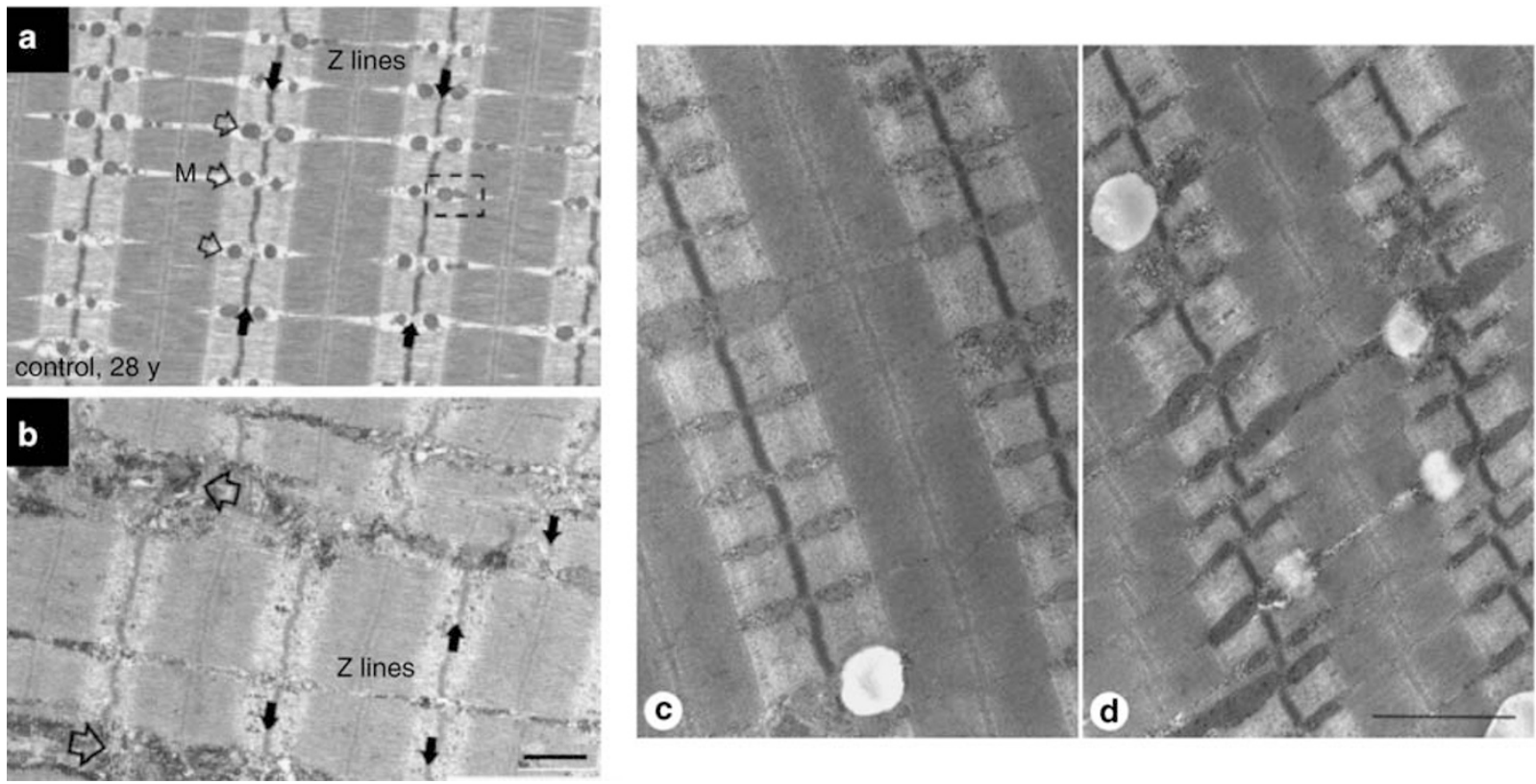

Figure 3 Left: Electron micrographs of longitudinal sections from muscle fibers of control (a) and long-term spastic patient (b). Skeletal muscles from control subjects were characterized by a highly ordered internal organization. The contractile apparatus was formed by sarcomeres, delimited by Z lines (black arrows in a) and well aligned with those of adjacent myofibrils. Muscle fibers from paralyzed patients showed partially lost precise alignment of sarcomeres of adjacent myofibrils (black arrows in b). Scale bars $=1 \mu \mathrm{m} .{ }^{72}$ Right: Electron micrographs of longitudinal sections of slow muscle fibers before (c) and after (d) a 17-day spaceflight. Preflight control fiber has wide myofibrils, whereas myofibrils postflight are thinner, indicating atrophy. Mitochondria- and glycogen-like granules are similar in both fibers, but lipid droplets (white spheres) are more frequent postflight. Postflight there is also partially lost alignment of sarcomeres of adjacent myofibrils. Scale bar $=1.5 \mu \mathrm{m} .{ }^{78}$ Note similarities between atrophy and loss of sarcomere alignment between individuals with $\mathrm{SCl}$ and astronauts postflight. (Figures reprinted with permission).

muscle atrophy in long-term paraplegics suggest that after an initial rapid progression, muscle atrophy reaches a steady state and likely plateaus. ${ }^{72}$ Furthermore, ultrastructural analysis of biopsies from long-term spastic patients showed that the myofibrillar apparatus is in general less ordered than in normal muscle. The misalignment of the contractile apparatus in paraplegic patients may explain why their strength and endurance is decreased when compared with normal subjects. Indeed, using functional electrical stimulation, it has been shown that there is an increase in muscle fatigability following SCI. $^{73}$ Interestingly, it has recently been shown that long-term neuromuscular electrical stimulation training programs can preserve the physiological properties of the plantar flexor muscles. ${ }^{74}$ This training protocol yielded significant improvements for the trained versus untrained limb in torque, torque-time integral, fatigue index, torque rise time and between-twitch fusion. These results show the importance of exercise as a countermeasure in maintaining muscular integrity in individuals with SCI.

There are similar decreases in muscle size and function after exposure to microgravity. LeBlanc et al. ${ }^{75}$ showed a $6 \%$ decrease in muscle volume following an 8-day spaceflight, whereas 6 months of spaceflight seems to result in a 13-17\% decrease in muscle mass. ${ }^{76,77}$ Following an 11-day human spaceflight, Edgerton et al. ${ }^{78}$ observed a significant decline in the CSAs of fibers from the vastus lateralis muscle, with decline being greatest in type IIb fibers and least in type I fibers. Widrick et al. ${ }^{79}$ made similar observations for the soleus muscle; following a 17-day flight, type IIa fiber CSAs declined by $26 \%$ compared with a $15 \%$ reduction in the CSAs of type I fiber. To our knowledge, there are no data that have examined muscle atrophy following spaceflight lasting more than 12 months. However, we hypothesize that, similar to SCI, there would be a plateau in atrophy. ${ }^{119}$ Short-term space flight (17 days) was found to reduce specific tension of soleus muscle fibers. ${ }^{80}$ Although human data from Skylab and Mir suggest that leg extensors atrophy and loose peak force faster than flexors, when flight duration is long enough ( $>200$ days) both groups of muscles show similar declines of $\sim 30 \%$ in isokinetic strength. ${ }^{73,79}$

Interestingly, in both patients with SCI and astronauts following spaceflight, there seem to be alterations in the contractile apparatus (Figure 3), which could also contribute to the impairment in muscle force. The left side in Figure 3 illustrates electron micrographs of longitudinal sections from muscle fibers of control (Figure 3a) and long-term spastic patient (Figure 3b). Skeletal muscles from control subjects were characterized by a highly ordered contractile apparatus, delimited by $\mathrm{Z}$ lines (black arrows in panel a) and well aligned with those of adjacent myofibrils. In contrast, muscle fibers from paralyzed patients showed partially lost, precise alignment of sarcomeres of adjacent myofibrils (black arrows in panel b). ${ }^{72}$ The right side of Figure 3 illustrates electron micrographs of longitudinal sections of muscle 


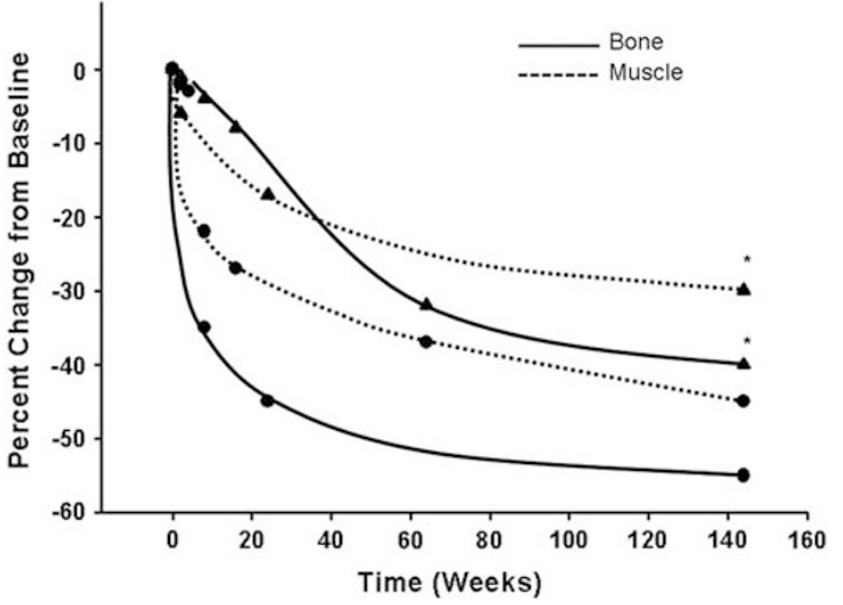

Figure 4 Timeline of muscle (dotted line) and bone (solid line) atrophy in $\mathrm{SCl}$ (circles) and spaceflight (triangles). Following $\mathrm{SCl}$, there is rapid atrophy of muscle $\mathrm{e}^{72}$ and bone. ${ }^{84}$ This atrophy plateaus after 1 year. ${ }^{72}$ Spaceflight results in slower progression of muscle ${ }^{119}$ and bone ${ }^{76}$ atrophy, which also likely plateaus. *Estimates based on reported literature of bone and muscle loss in microgravity.

fibers before (Figure 3c) and after (Figure 3d) a 17-day spaceflight. Preflight control fiber had wide myofibrils, whereas myofibrils postflight were thinner, indicating atrophy. Furthermore, lipid droplets (white spheres) were more frequent postflight, accompanied by partially lost alignment of sarcomeres of adjacent myofibrils. ${ }^{78}$ It is important to note similarities in atrophy and loss of sarcomere alignment between individuals with SCI and astronauts postflight.

Although both SCI and spaceflight lead to a decrease in muscle mass, a fundamental difference is believed to exist between disuse and denervation atrophy. Although denervation atrophy results from injury to motor neurons in the spinal cord or to the motor nerves in the ventral roots through which they exit, ${ }^{81}$ disuse atrophy occurs as a result of loss of muscle activation. ${ }^{82}$ Although denervation atrophy occurs solely in individuals with SCI, both SCI and spaceflight result in disuse atrophy. Disuse atrophy is more pronounced in extensor muscles that normally bear weight, especially those that cross single joints. ${ }^{70,83}$ The dotted lines in Figure 4 illustrate differences in muscle mass between denervation atrophy of SCI (circles) and disuse atrophy of microgravity (triangles). Denervation atrophy seems to result in rapid loss of muscle mass followed by a plateau, whereas muscle loss from disuse atrophy occurs more slowly.

\section{Bone loss}

Considerable evidence exists showing the association between bone loss and both physical inactivity and decreased mechanical loading in individuals living with SCI (the reader is referred to several in depth reviews on the topic). ${ }^{84-86}$ Briefly, rate of bone loss after SCI is rapid and linear in the acute stages, establishing a lower steady-state bone mass level 1-2 years after the event.$^{87}$ In individuals with SCI in less than 1 year following the injury, reduction in bone mineral density (BMD) has been noted in the femoral neck (27\%), midshaft (25\%) and distal femur (43\%), as compared with controls. Bone mineral loss continues, but to a lesser degree, in the pelvis and lower extremities over the next 10 years, resulting in demineralization of over $50 \%$ by 10 years after injury. ${ }^{88}$ In contrast to lower limbs, arms and trunk show an increase in bone content after the 4-month point, consequently resulting in a net effect of $\sim 10-21 \%$ total loss of bone at the 10 -year point. ${ }^{89}$ In individuals with SCI, distal femur and proximal tibia (knee region) are mostly at risk, consistent with site-specific decreases in BMD such that fractures of the distal femur are referred to as 'the paraplegic fracture' ${ }^{90}$ Several investigations have reported an incidence of up to $34 \%$ of lower extremity fractures in patients with SCI. ${ }^{91,92}$ Low-energy fractures in individuals with SCI have been reported to occur during events that would not normally cause fractures among able-bodied individuals, such as a transfer from bed to chair or being turned in bed. ${ }^{90}$ Common fracture sites appear to be those around the knee, such as the distal femur or proximal tibia. ${ }^{93,94}$

Interestingly, although spaceflight also results in bone atrophy, progression and magnitude of loss differs from SCI. The solid lines in Figure 4 illustrate differences between SCI (circles) and microgravity (triangles) induced bone loss. Note that SCI results in rapid loss of bone followed by a plateau, whereas bone loss from microgravity exposure occurs more slowly. Skeletal unloading in astronauts can result in a loss of as much as $1-2 \%$ per month of BMD. ${ }^{89,95}$ On the Mir yearlong mission, bone measurements of astronauts showed a $10 \%$ reduction of lumbar vertebrae as compared with preflight. ${ }^{76}$ Consequently, on an approximately 3-year manned mission to Mars, it is anticipated that astronauts could have significant BMD loss in select locations. Sites of BMD loss are also similar between individuals with SCI and astronauts. Demineralization in spaceflight also predominates in long bones of the lower limbs, with maximal bone loss occurring in calcaneus and hip. ${ }^{96}$ The main concern with this significant loss of BMD for astronauts is bone fracture. With limited medical resources available during a mission, a fracture could be detrimental to a mission and even life threatening for the astronaut.

\section{Mechanism of bone loss}

The mechanism responsible for loss of bone mass is yet to be clarified. After SCI, bone formation markers (osteoblasts) remain at normal or slightly higher than normal levels. ${ }^{97}$ However, high levels of alkaline phosphatase, which have been reported during the first year after injury in individuals with SCI may reflect high levels of overall bone turnover. ${ }^{98}$ In addition, notable increases in bone resorption markers (osteoclasts) have been reported to occur as early as 2 weeks, reaching peak values 2-4 months after SCI onset. ${ }^{91}$ These studies suggest that bone resorption increases after SCI with only small changes in bone formation, and that elevated resorption may persist beyond the acute stages of injury.

Bone resorption markers are also reportedly increased during and following spaceflight, ${ }^{99,100}$ whereas bone formation markers may be unchanged or decreased after flight. ${ }^{101}$ 
Thus, it is not clear whether the bone loss is associated with reduced bone remodeling or an uncoupling between bone formation and resorption in microgravity. Other factors such as alterations in systemic hormones such as calcitonin, testosterone and parathyroid hormone have also been suggested to contribute to a decrease in BMD during spaceflight. ${ }^{102}$

\section{Alterations in other systems}

Although much research has been focused on the consequences of SCI and microgravity on cardiovascular and musculoskeletal health, other systems are also dramatically affected. Neurovestibular and sensory motor function are severely altered following SCI, and changes to these systems may impair the ability of a crew to leave the space vehicle in an emergency situation after landing. ${ }^{2}$ Individuals with SCI and astronauts may also be at a greater risk of developing renal stones due to immobilization and metabolic alterations. Finally, one of the important systems affected by spaceflight and SCI is the regulation of the immune response, which could have profound effects on the ability of the host to resist infection and tumors.

\section{Neurovestibular and sensory motor dysfunction}

For the motor system to function effectively, a continuous inflow of sensory information is necessary to allow the body to select appropriate responses and to make adjustments in ongoing movements. Vision, hearing and receptors on the body surface inform the motor systems about events in the environment. Proprioceptors in muscles, joints and vestibular apparatus inform about position and orientation of the body and limbs, and degree of contraction of the muscles. In SCI, communication between supraspinal centers and muscles below the level of the lesion is often completely absent. ${ }^{103}$ In other words, command inputs from the brain do not reach the muscles. As the motor systems do not have proprioceptive information available to them, losses occur not only in motor functions but also in sensory ones. Consequently, visual cues become much more significant following SCI.

Spaceflight may negatively affect neurovestibular and sensorimotor functions, particularly posture and locomotor control, gaze stabilization and spatial orientation. ${ }^{104,105}$ Disturbances in neurovestibular and sensorimotor functions can result in degraded performance of operational tasks on orbit, inability to perform emergency egress, and impairments in performing normal daily activities for varying periods after landing. Absence of gravitational stimulation of the otolith organ seems to be heavily implicated in the observed neurovestibular effects. This is thought to contribute to sensory conflict and may interfere with central processing tasks associated with visuomotor skills. Over time, similar to SCI, the central nervous system is apparently able to adapt by reweighting sensory inputs - relying more heavily on visual cues than proprioceptive and otolithic inputs. However, this adaptation is not complete, as is shown by the deficits observed. ${ }^{104-107}$

\section{Renal stones}

Patients with SCI are more prone to develop chronic and complicated stone disease over their lifetime, with $7 \%$ experiencing an episode within 10 years of injury. ${ }^{108}$ In this patient cohort, unrecognized stone disease can contribute to renal failure, a significant source of morbidity and mortality. ${ }^{109}$ In a case-control study, Favazza et al. ${ }^{109}$ reported that patients forming stones were older and were more likely to have complete injuries than patients known to be stone-free. DeVivo et al. ${ }^{110}$ noted that patients who developed renal stones were more likely to be older, have neurologically complete quadriplegia and have a history of bladder stones.

Although no known cases of renal stones have been reported during spaceflight, NASA astronauts have experienced 14 renal stone episodes, including multiple events experienced by one crewmember. ${ }^{111,112}$ There is a growing body of evidence from NASA and the Russian space program showing that humans exposed to the microgravity environment of space also have a greater risk for developing renal stones. ${ }^{100,113}$ Should such stones develop on long-duration missions, debilitating pain accompanying the stone incident would result in functional loss of the crew member and that person's contribution to overall success of the mission. Lack of facilities for in-flight treatment of a stone episode could furthermore necessitate aborting the mission and initiating a rapid return to Earth.

Although stone formation in low urinary tract is poorly understood, there is some evidence implicating the role of hypercalciuria in this process. With an increased breakdown of BMD, spaceflight and SCI result in chronic changes in calcium balance. ${ }^{111,112}$ Decreased fluid intake and decreased urine volume, both commonly observed following SCI and spaceflight, may increase the risk for renal stones. ${ }^{114}$ Consequently, proper hydration is an important countermeasure to prevent renal stone formation.

\section{Immune dysfunction}

Alterations in immune system have been shown to occur along with other physiological changes associated with spaceflight and SCI. ${ }^{115,116}$ Individuals with SCI have decreased natural and adaptive immune function and reduced blood levels of cellular adhesion molecules that participate in immune function and wound healing. ${ }^{117,118}$ SCI might affect immune cells and immune responsiveness by (1) disrupting the outflow of signals from the sympathetic nervous system to lymphoid tissues and their blood vessels, as well as returning afferent signals from these tissues to the brain; (2) immunosuppression caused by stressors affecting patients with SCI; (3) interrupting returning signals to the central nervous system from the periphery, thereby reducing facilitation of immunoregulatory central nervous system neurons and decreasing their activity; or a combination of all three. ${ }^{115,116}$

Altered white blood cell subpopulations, decreased proliferation of immune cells and altered production of immunoregulatory molecules have also been documented during and immediately after spaceflight. ${ }^{120}$ The mechanisms and biomedical consequences of these changes remain 


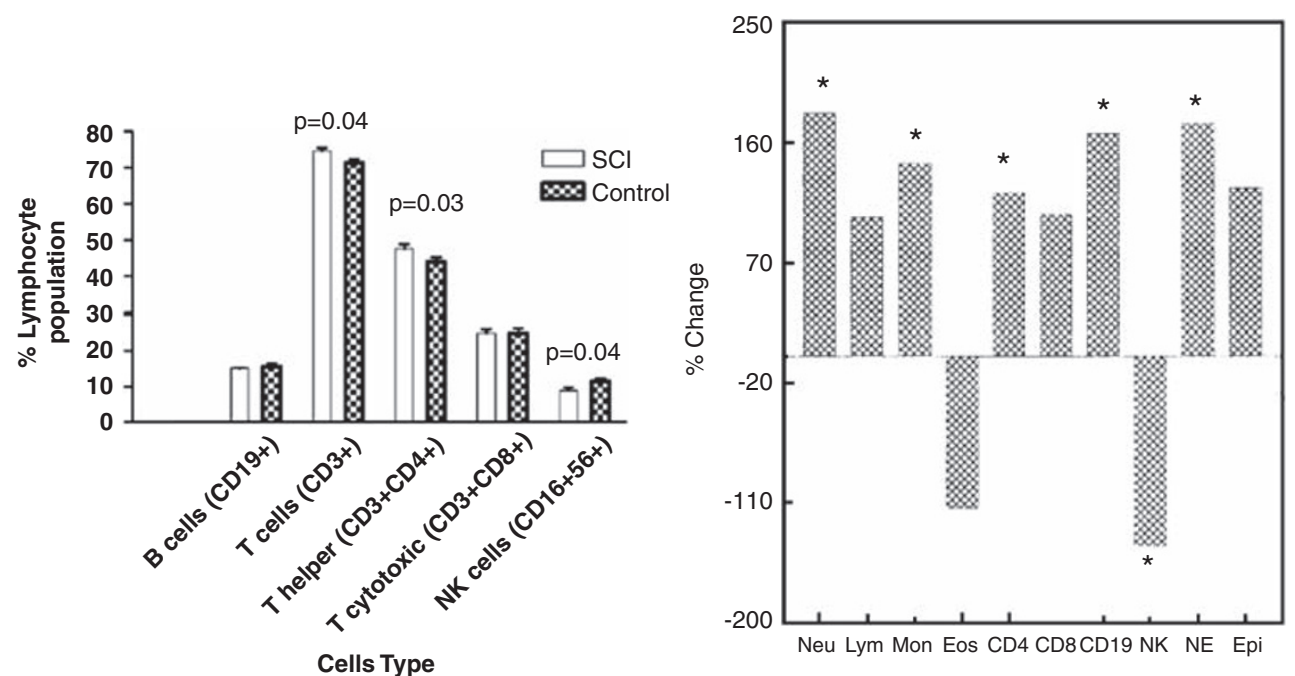

Figure 5 Left: Percent cell types of the total lymphocyte population in SCl (open bar) and controls (hatched bars) (mean \pm s.e.). ${ }^{115}$ Right: Percentage change in number of circulating leukocytes and levels of catecholamines among 11 astronauts after landing (R_0) as compared with preflight $\left(L_{-} 10\right)$ values. ${ }^{120} * P<0.05$ versus preflight. Note the similarities in the increase in lymphocyte population and the decrease in natural killer cell population between individuals with $\mathrm{SCl}$ and astronauts postflight. (Figures reprinted with permission).

to be established, although possible causes of spaceflightinduced alterations in immune responses include exposure to stress and exposure to radiation.

Figure 5 illustrates these alterations in immune function following SCI and spaceflight. The left graph presents a significant difference between preflight and postflight in percent cell types of the total lymphocyte population in SCI (open bars) and controls (hatched bars), ${ }^{115}$ whereas the right graph shows a significant percentage change in the number of circulating leukocytes among 11 astronauts after landing (R_0) as compared with preflight (L_10) values. ${ }^{120}$ Note the similarities in the increase in lymphocyte population and the decrease in natural killer cells population between individuals with SCI and astronauts postflight.

Overall, these data suggest that a dysregulation of the immune system occurs in SCI and spaceflight, and that these changes may increase the risks of infection, increase the reactivation of latent viruses, and potentially alter immune surveillance and the incidence of autoimmune disease or tumorigenesis. As the space program moves to longer exploratory missions, importance of the observed immune system changes will increase dramatically.

\section{Microgravity and SCl: similar but not the same}

Although we presented various similarities in health and physiological outcomes among individuals with SCI and astronauts, there are also significant differences between the two conditions that must be considered. Individuals with SCI cannot stand up because of paralysis, and have only limited gravity exposure when seated in a wheelchair, whereas astronauts are continuously exposed to microgravity during spaceflight. Accordingly, it is difficult to separate hypokinesis effects from those associated with reduced gravitational stress. The most crucial difference between the groups is trauma to the spinal cord and associated dysfunctions present in individuals with SCI. For example, loss of motor control by supraspinal structures results in paralysis and inability of an individual to stand up or exercise. This is clearly not the case in astronauts, who have an intact central nervous system. A lack of supraspinal input to spinal autonomic control is another physiological difference. Although both groups experience orthostatic intolerance, there is a decline in resting muscle sympathetic activity in individuals with SCI, and an increase in muscle sympathetic nerve activity in microgravity. Another consideration is the fact that changes observed in astronauts after long exposure to microgravity are largely reversible, which is often not the case for individuals with SCI. In summary, discrepancies in study design, magnitude of change and lack of information with regard to long-term adaptations in SCI and spaceflight limit comparisons. These distinctions are important to take into account when designing and implementing countermeasures for both SCI and spaceflight.

\section{Conclusion}

There are striking similarities between cardiovascular, musculoskeletal and other system alterations that occur following SCI and exposure to microgravity (Table 1). Both SCI and spaceflight result in decreased baroreceptor function and alterations in salt and water balance, two mechanisms contributing to orthostatic intolerance. However, following SCI the loss of central tonic sympathetic control is also a major factor contributing to orthostatic intolerance. Decreased BMD is due to an increase in osteoclast function in both conditions. Spaceflight results in disuse muscle atrophy, whereas SCI causes muscle atrophy through both denervation and disuse mechanisms. Finally, spaceflight and SCI lead to decreases in immune function, an increased 
risk of renal stone formation, and alterations in neurovestibular and sensory motor systems. These similarities occurring in two discrete populations may result in an increasing number of clinicians choosing to use research facilities aboard the international space station to better understand the ways of preventing some of the negative physiological consequences of SCI. So too, life scientists may look to Earth-based models to explore the consequences of microgravity. Investigations may be limited by availability of data from astronauts and animals flown in space, as well as the difficulties in performing long-term bed rest investigations in humans. In the interim, ground-based models based on SCI may be used for investigations examining the physiological mechanisms underlying disuse. Conversely, as space exploration becomes more frequent, opportunities to explore physiological changes associated with spaceflight will expand and may replace other models in evaluation of the effect of reduced gravitational forces.

\section{Conflict of interest}

The authors declare no conflict of interest.

\section{Acknowledgements}

Dr Warburton is supported by a career award from the Canadian Institutes of Health Research and is a Michael Smith Foundation for Health Research (MSFHR) Clinical Scholar. Dr Krassioukov is supported by International Collaboration on Repair Discoveries, the Heart and Stroke Foundation, and Christopher and Dana Reeve Foundation. Jessica Scott was supported by doctoral graduate scholarships from the Natural Sciences and Engineering Research Council of Canada and the MSFHR.

\section{References}

1 Krassioukov A, Claydon VE. The clinical problems in cardiovascular control following spinal cord injury: an overview. Prog Brain Res 2006; 152: 223-229.

2 Williams D, Kuipers A, Mukai C, Thirsk R. Acclimation during space flight: effects on human physiology. CMAJ 2009; 180: 1317-1323.

3 Dietz V, Colombo G. Recovery from spinal cord injury-underlying mechanisms and efficacy of rehabilitation. Acta Neurochir Suppl 2004; 89: 95-100.

4 Meck JV, Reyes CJ, Perez SA, Goldberger AL, Ziegler MG. Marked exacerbation of orthostatic intolerance after long- vs shortduration spaceflight in veteran astronauts. Psychosom Med 2001; 63: 865-873.

5 Claydon VE, Steeves JD, Krassioukov A. Orthostatic hypotension following spinal cord injury: understanding clinical pathophysiology. Spinal Cord 2006; 44: 341-351.

6 The Consensus Committee of the American Autonomic Society and the American Academy of Neurology. Consensus statement on the definition of orthostatic hypotension, pure autonomic failure, and multiple system atrophy. Neurology 1996; 46: 1470.

7 Mathias CJ, Mallipeddi R, Bleasdale-Barr K. Symptoms associated with orthostatic hypotension in pure autonomic failure and multiple system atrophy. J Neurol 1999; 246: 893-898.

8 Illman A, Stiller K, Williams M. The prevalence of orthostatic hypotension during physiotherapy treatment in patients with an acute spinal cord injury. Spinal Cord 2000; 38: 741-747.
9 Buckey Jr JC, Lane LD, Levine BD, Watenpaugh DE, Wright SJ, Moore WE et al. Orthostatic intolerance after spaceflight. J Appl Physiol 1996; 81: 7-18.

10 Hargens AR, Richardson S. Cardiovascular adaptations, fluid shifts, and countermeasures related to space flight. Respir Physiol Neurobiol 2009; 169(Suppl 1): S30-S33.

11 Wallin BG, Stjernberg L. Sympathetic activity in man after spinal cord injury. Outflow to skin below the lesion. Brain 1984; 107 (Part 1): 183-198.

12 Teasell RW, Arnold JM, Krassioukov A, Delaney GA. Cardiovascular consequences of loss of supraspinal control of the sympathetic nervous system after spinal cord injury. Arch Phys Med Rehabil 2000; 81: 506-516.

13 Mathias CJ, Christensen NJ, Frankel HL, Peart WS. Renin release during head-up tilt occurs independently of sympathetic nervous activity in tetraplegic man. Clin Sci (Lond) 1980; 59: 251-256.

14 Hainsworth R. Heart rate and orthostatic stress. Clin Auton Res 2000; 10: 323-325.

15 Leach CS, Altchuler SI, Cintron-Trevino NM. The endocrine and metabolic responses to space flight. Med Sci Sports Exerc 1983; 15: 432-440.

16 Leach CS, Alfrey CP, Suki WN, Leonard JI, Rambaut PC, Inners LD et al. Regulation of body fluid compartments during shortterm spaceflight. J Appl Physiol 1996; 81: 105-116.

17 Norsk P, Drummer C, Rocker L, Strollo F, Christensen NJ, Warberg $\mathrm{J}$ et al. Renal and endocrine responses in humans to isotonic saline infusion during microgravity. J Appl Physiol 1995; 78: 2253-2259.

18 Eckberg DL. Bursting into space: alterations of sympathetic control by space travel. Acta Physiol Scand 2003; 177: 299-311.

19 Lathers CM, Charles JB, Schneider VS, Frey MA, Fortney S. Use of lower body negative pressure to assess changes in heart rate response to orthostatic-like stress during 17 weeks of bed rest. J Clin Pharmacol 1994; 34: 563-570.

20 Fritsch-Yelle JM, Charles JB, Jones MM, Wood ML. Microgravity decreases heart rate and arterial pressure in humans. J Appl Physiol 1996; 80: 910-914.

21 Blaber AP, Bondar RL, Kassam MS. Heart rate variability and short duration spaceflight: relationship to post-flight orthostatic intolerance. BMC Physiol 2004; 4: 6.

22 Crandall CG, Engelke KA, Pawelczyk JA, Raven PB, Convertino VA. Power spectral and time based analysis of heart rate variability following 15 days head-down bed rest. Aviat Space Environ Med 1994; 65: 1105-1109.

23 Hughson RL, Maillet A, Gharib C, Fortrat JO, Yamamoto Y, PavyLetraon A et al. Reduced spontaneous baroreflex response slope during lower body negative pressure after 28 days of head-down bed rest. J Appl Physiol 1994; 77: 69-77.

24 Munakata M, Kameyama J, Nunokawa T, Ito N, Yoshinaga K. Altered Mayer wave and baroreflex profiles in high spinal cord injury. Am J Hypertens 2001; 14: 141-148.

25 Convertino VA, Adams WC, Shea JD, Thompson CA, Hoffler GW. Impairment of carotid-cardiac vagal baroreflex in wheelchairdependent quadriplegics. Am J Physiol 1991; 260: R576-R580.

26 Wecht JM, De Meersman RE, Weir JP, Spungen AM, Bauman WA. Cardiac autonomic responses to progressive head-up tilt in individuals with paraplegia. Clin Auton Res 2003; 13: 433-438.

27 Aslan SC, Randall DC, Donohue KD, Knapp CF, Patwardhan AR, McDowell SM et al. Blood pressure regulation in neurally intact human vs acutely injured paraplegic and tetraplegic patients during passive tilt. Am J Physiol Regul Integr Comp Physiol 2007; 292: R1146-R1157.

28 Fritsch JM, Charles JB, Bennett BS, Jones MM, Eckberg DL. Shortduration spaceflight impairs human carotid baroreceptor-cardiac reflex responses. J Appl Physiol 1992; 73: 664-671.

29 Fritsch-Yelle JM, Charles JB, Jones MM, Beightol LA, Eckberg DL. Spaceflight alters autonomic regulation of arterial pressure in humans. J Appl Physiol 1994; 77: 1776-1783.

30 Cox JF, Tahvanainen KU, Kuusela TA, Levine BD, Cooke WH, Mano $\mathrm{T}$ et al. Influence of microgravity on astronauts' sympathetic and vagal responses to Valsalva's manoeuvre. J Physiol 2002; 538: 309-320. 
31 Claydon VE, Norcliffe LJ, Moore JP, Rivera-Ch M, Leon-Velarde F, Appenzeller $\mathrm{O}$ et al. Orthostatic tolerance and blood volumes in Andean high altitude dwellers. Exp Physiol 2004; 89: 565-571.

32 Claydon VE, Hainsworth R. Salt supplementation improves orthostatic cerebral and peripheral vascular control in patients with syncope. Hypertension 2004; 43: 809-813.

33 Karlsson AK, Krassioukov AV. Hyponatremia-induced transient visual disturbances in acute spinal cord injury. Spinal Cord 2004; 42: 204-207.

34 Houtman S, Oeseburg B, Hopman MT. Blood volume and hemoglobin after spinal cord injury. Am J Phys Med Rehabil 2000; 79: 260-265.

35 Groomes TE, Huang CT. Orthostatic hypotension after spinal cord injury: treatment with fludrocortisone and ergotamine. Arch Phys Med Rehabil 1991; 72: 56-58.

36 Diedrich A, Paranjape SY, Robertson D. Plasma and blood volume in space. Am J Med Sci 2007; 334: 80-85.

37 de Groot PC, van Dijk A, Dijk E, Hopman MT. Preserved cardiac function after chronic spinal cord injury. Arch Phys Med Rehabil 2006; 87: 1195-1200.

38 Nash MS, Bilsker S, Marcillo AE, Isaac SM, Botelho LA, Klose KJ et al. Reversal of adaptive left ventricular atrophy following electrically-stimulated exercise training in human tetraplegics. Paraplegia 1991; 29: 590-599.

39 Perhonen MA, Franco F, Lane LD, Buckey JC, Blomqvist CG, Zerwekh JE et al. Cardiac atrophy after bed rest and spaceflight. J Appl Physiol 2001; 91: 645-653.

40 Levine BD, Zuckerman JH, Pawelczyk JA. Cardiac atrophy after bed-rest deconditioning: a nonneural mechanism for orthostatic intolerance. Circulation 1997; 96: 517-525.

41 Lehmann KG, Lane JG, Piepmeier JM, Batsford WP. Cardiovascular abnormalities accompanying acute spinal cord injury in humans: incidence, time course and severity. J Am Coll Cardiol 1987; 10: 46-52.

42 Winslow EB, Lesch M, Talano JV, Meyer Jr PR. Spinal cord injuries associated with cardiopulmonary complications. Spine (Phila Pa 1976) 1986; 11: 809-812.

43 Furlan JC, Fehlings MG, Shannon P, Norenberg MD, Krassioukov AV. Descending vasomotor pathways in humans: correlation between axonal preservation and cardiovascular dysfunction after spinal cord injury. J Neurotrauma 2003; 20: 1351-1363.

44 Furlan JC, Krassioukov AV, Fehlings MG. The effects of gender on clinical and neurological outcomes after acute cervical spinal cord injury. J Neurotrauma 2005; 22: 368-381.

45 Collins HL, Rodenbaugh DW, DiCarlo SE. Spinal cord injury alters cardiac electrophysiology and increases the susceptibility to ventricular arrhythmias. Prog Brain Res 2006; 152: 275-288.

46 Claydon VE, Elliott SL, Sheel AW, Krassioukov A. Cardiovascular responses to vibrostimulation for sperm retrieval in men with spinal cord injury. J Spinal Cord Med 2006; 29: 207-216.

47 Fritsch-Yelle JM, Leuenberger UA, D'Aunno DS, Rossum AC, Brown TE, Wood ML et al. An episode of ventricular tachycardia during long-duration spaceflight. Am J Cardiol 1998; 81: 1391-1392.

48 D'Aunno DS, Dougherty AH, DeBlock HF, Meck JV. Effect of short- and long-duration spaceflight on QTc intervals in healthy astronauts. Am J Cardiol 2003; 91: 494-497.

49 Convertino VA. Status of cardiovascular issues related to space flight: implications for future research directions. Respir Physiol Neurobiol 2009; 169(Suppl 1): S34-S37.

50 Folkow B. Structure and function of the arteries in hypertension. Am Heart J 1987; 114: 938-948.

51 Vane JR, Anggard EE, Botting RM. Regulatory functions of the vascular endothelium. $N$ Engl J Med 1990; 323: 27-36.

52 Celermajer DS, Sorensen KE, Gooch VM, Spiegelhalter DJ, Miller OI, Sullivan ID et al. Non-invasive detection of endothelial dysfunction in children and adults at risk of atherosclerosis. Lancet 1992; 340: 1111-1115.

53 Furchgott RF, Zawadzki JV. The obligatory role of endothelial cells in the relaxation of arterial smooth muscle by acetylcholine. Nature 1980; 288: 373-376.

54 Anderson TJ, Uehata A, Gerhard MD, Meredith IT, Knab S, Delagrange $\mathrm{D}$ et al. Close relation of endothelial function in the human coronary and peripheral circulations. I Am Coll Cardio 1995; 26: 1235-1241.

55 Schroeder S, Enderle MD, Ossen R, Meisner C, Baumbach A, Pfohl $\mathrm{M}$ et al. Noninvasive determination of endotheliummediated vasodilation as a screening test for coronary artery disease: pilot study to assess the predictive value in comparison with angina pectoris, exercise electrocardiography, and myocardial perfusion imaging. Am Heart J 1999; 138: 731-739.

56 De Groot PC, Van Kuppevelt DH, Pons C, Snoek G, Van Der Woude LH, Hopman MT. Time course of arterial vascular adaptations to inactivity and paralyses in humans. Med Sci Sports Exerc 2003; 35: 1977-1985.

57 Grey E, Bratteli C, Glasser SP, Alinder C, Finkelstein SM, Lindgren BR et al. Reduced small artery but not large artery elasticity is an independent risk marker for cardiovascular events. Am J Hypertens 2003; 16: 265-269.

58 Hesse C, Siedler H, Luntz SP, Arendt BM, Goerlich R, Fricker R et al. Modulation of endothelial and smooth muscle function by bed rest and hypoenergetic, low-fat nutrition. J Appl Physiol 2005; 99: 2196-2203.

59 Coupe M, Fortrat JO, Larina I, Gauquelin-Koch G, Gharib C, Custaud MA. Cardiovascular deconditioning: from autonomic nervous system to microvascular dysfunctions. Respir Physiol Neurobiol 2009; 169(Suppl 1): S10-S12.

60 Expert Panel on Detection, Evaluation, And Treatment of High Blood Cholesterol in Adults (Adult Treatment Panel III). Executive Summary of The Third Report of The National Cholesterol Education Program (NCEP). JAMA 2001; 285: 2486-2497.

61 Manns PJ, McCubbin JA, Williams DP. Fitness, inflammation, and the metabolic syndrome in men with paraplegia. Arch Phys Med Rehabil 2005; 86: 1176-1181.

62 Brenes G, Dearwater S, Shapera R, LaPorte RE, Collins E. High density lipoprotein cholesterol concentrations in physically active and sedentary spinal cord injured patients. Arch Phys Med Rehabil 1986; 67: 445-450.

63 Bauman WA, Adkins RH, Spungen AM, Herbert R, Schechter C, Smith D et al. Is immobilization associated with an abnormal lipoprotein profile? Observations from a diverse cohort. Spinal Cord 1999; 37: 485-493.

64 Apstein MD, George BC. Serum lipids during the first year following acute spinal cord injury. Metabolism 1998; 47: 367-370.

65 Cardus D, Ribas-Cardus F, McTaggart WG. Lipid profiles in spinal cord injury. Paraplegia 1992; 30: 775-782.

66 Bauman WA, Spungen AM. Metabolic changes in persons after spinal cord injury. Phys Med Rehabil Clin N Am 2000; 11: 109-140.

67 Leach CS, Lane HW, Krauhs JM. Short-term space flight on nitrogenous compounds, lipoproteins, and serum proteins. J Clin Pharmacol 1994; 34: 500-509.

68 Markin A, Strogonova L, Balashov O, Polyakov V, Tigner T. The dynamics of blood biochemical parameters in cosmonauts during long-term space flights. Acta Astronaut 1998; 42: 247-253.

69 Castro MJ, Apple Jr DF, Hillegass EA, Dudley GA. Influence of complete spinal cord injury on skeletal muscle cross-sectional area within the first 6 months of injury. Eur J Appl Physiol Occup Physiol 1999; 80: 373-378.

70 Wilmet E, Ismail AA, Heilporn A, Welraeds D, Bergmann P. Longitudinal study of the bone mineral content and of soft tissue composition after spinal cord section. Paraplegia 1995; 33: 674-677.

71 Spungen AM, Wang J, Pierson Jr RN, Bauman WA. Soft tissue body composition differences in monozygotic twins discordant for spinal cord injury. J Appl Physiol 2000; 88: 1310-1315.

72 Kern H, Hofer C, Modlin M, Mayr W, Vindigni V, Zampieri S et al. Stable muscle atrophy in long-term paraplegics with complete upper motor neuron lesion from 3- to 20-year SCI. Spinal Cord 2008; 46: 293-304.

73 Fitts RH, Riley DR, Widrick JJ. Functional and structural adaptations of skeletal muscle to microgravity. J Exp Biol 2001; 204: 3201-3208.

74 Shields RK, Dudley-Javoroski S. Musculoskeletal adaptations in chronic spinal cord injury: effects of long-term soleus electrical stimulation training. Neurorehabil Neural Repair 2007; 21: 169-179. 
75 LeBlanc A, Rowe R, Schneider V, Evans H, Hedrick T. Regional muscle loss after short duration spaceflight. Aviat Space Environ Med 1995; 66: 1151-1154.

76 LeBlanc A, Schneider V, Shackelford L, West S, Oganov V, Bakulin A et al. Bone mineral and lean tissue loss after long duration space flight. J Musculoskelet Neuronal Interact 2000; 1: 157-160.

77 Trappe S, Costill D, Gallagher P, Creer A, Peters JR, Evans H et al. Exercise in space: human skeletal muscle after 6 months aboard the International Space Station. J Appl Physiol 2009; 106: 1159-1168.

78 Edgerton VR, Zhou MY, Ohira Y, Klitgaard H, Jiang B, Bell G et al. Human fiber size and enzymatic properties after 5 and 11 days of spaceflight. J Appl Physiol 1995; 78: 1733-1739.

79 Widrick JJ, Knuth ST, Norenberg KM, Romatowski JG, Bain JL, Riley DA et al. Effect of a 17 day spaceflight on contractile properties of human soleus muscle fibres. J Physiol 1999; 516 (Part 3): 915-930.

80 Greenleaf JE, Bernauer EM, Ertl AC, Trowbridge TS, Wade CE. Work capacity during 30 days of bed rest with isotonic and isokinetic exercise training. J Appl Physiol 1989; 67: 1820-1826.

81 Roy RR, Baldwin KM, Edgerton VR. The plasticity of skeletal muscle: effects of neuromuscular activity. Exerc Sport Sci Rev 1991; 19: 269-312.

82 Gordon T, Mao J. Muscle atrophy and procedures for training after spinal cord injury. Phys Ther 1994; 74: 50-60.

83 Negredo P, Rivero JL, Gonzalez B, Ramon-Cueto A, Manso R. Slow- and fast-twitch rat hind limb skeletal muscle phenotypes 8 months after spinal cord transection and olfactory ensheathing glia transplantation. J Physiol 2008; 586: 2593-2610.

84 Giangregorio L, McCartney N. Bone loss and muscle atrophy in spinal cord injury: epidemiology, fracture prediction, and rehabilitation strategies. J Spinal Cord Med 2006; 29: 489-500.

85 Dudley-Javoroski S, Shields RK. Muscle and bone plasticity after spinal cord injury: review of adaptations to disuse and to electrical muscle stimulation. J Rehabil Res Dev 2008; 45: 283-296.

86 Maimoun L, Fattal C, Micallef JP, Peruchon E, Rabischong P. Bone loss in spinal cord-injured patients: from physiopathology to therapy. Spinal Cord 2006; 44: 203-210.

87 Garland DE, Stewart CA, Adkins RH, Hu SS, Rosen C, Liotta FJ et al. Osteoporosis after spinal cord injury. J Orthop Res 1992; 10: 371-378.

88 Reiter AL, Volk A, Vollmar J, Fromm B, Gerner HJ. Changes of basic bone turnover parameters in short-term and long-term patients with spinal cord injury. Eur Spine J 2007; 16: 771-776.

89 Lang T, LeBlanc A, Evans H, Lu Y, Genant H, Yu A. Cortical and trabecular bone mineral loss from the spine and hip in longduration spaceflight. J Bone Miner Res 2004; 19: 1006-1012.

90 Comarr AE, Hutchinson RH, Bors E. Extremity fractures of patients with spinal cord injuries. Am J Surg 1962; 103: 732-739.

91 Vestergaard P, Krogh K, Rejnmark L, Mosekilde L. Fracture rates and risk factors for fractures in patients with spinal cord injury. Spinal Cord 1998; 36: 790-796.

92 Freehafer AA, Hazel CM, Becker CL. Lower extremity fractures in patients with spinal cord injury. Paraplegia 1981; 19: 367-372.

93 de Bruin ED, Dietz V, Dambacher MA, Stussi E. Longitudinal changes in bone in men with spinal cord injury. Clin Rehabil 2000; 14: 145-152.

94 Eser P, Frotzler A, Zehnder Y, Denoth J. Fracture threshold in the femur and tibia of people with spinal cord injury as determined by peripheral quantitative computed tomography. Arch Phys Med Rehabil 2005; 86: 498-504

95 Biering-Sorensen F, Bohr HH, Schaadt OP. Longitudinal study of bone mineral content in the lumbar spine, the forearm and the lower extremities after spinal cord injury. Eur J Clin Invest 1990; 20: 330-335.

96 Grigoriev AI, Bugrov SA, Bogomolov VV, Egorov AD, Kozlovskaya IB, Pestov ID et al. Preliminary medical results of the Mir year-long mission. Acta Astronaut 1991; 23: 1-8.

97 Bergmann P, Heilporn A, Schoutens A, Paternot J, Tricot A. Longitudinal study of calcium and bone metabolism in paraplegic patients. Paraplegia 1977; 15: 147-159.

98 Maimoun L, Couret I, Micallef JP, Peruchon E, Mariano-Goulart $\mathrm{D}$, Rossi $\mathrm{M}$ et al. Use of bone biochemical markers with dual- energy X-ray absorptiometry for early determination of bone loss in persons with spinal cord injury. Metabolism 2002; 51: 958-963.

99 Collet P, Uebelhart D, Vico L, Moro L, Hartmann D, Roth M et al. Effects of 1- and 6-month spaceflight on bone mass and biochemistry in two humans. Bone 1997; 20: 547-551.

100 Heer M, Kamps N, Biener C, Korr C, Boerger A, Zittermann A et al. Calcium metabolism in microgravity. Eur J Med Res 1999; 4: 357-360.

101 Rucci N, Migliaccio S, Zani BM, Taranta A, Teti A. Characterization of the osteoblast-like cell phenotype under microgravity conditions in the NASA-approved rotating wall vessel bioreactor (RWV). J Cell Biochem 2002; 85: 167-179.

102 Uebelhart D, Demiaux-Domenech B, Roth M, Chantraine A. Bone metabolism in spinal cord injured individuals and in others who have prolonged immobilisation. A review. Paraplegia 1995; 33: 669-673.

103 Ivanenko YP, Poppele RE, Lacquaniti F. Distributed neural networks for controlling human locomotion: lessons from normal and SCI subjects. Brain Res Bull 2009; 78: 13-21.

104 Bacal K, Billica R, Bishop S. Neurovestibular symptoms following space flight. J Vestib Res 2003; 13: 93-102.

105 Clement G, Reschke M, Wood S. Neurovestibular and sensorimotor studies in space and Earth benefits. Curr Pharm Biotechnol 2005; 6: 267-283.

106 Holstein GR, Kukielka E, Martinelli GP. Anatomical observations of the rat cerebellar nodulus after $24 \mathrm{~h}$ of spaceflight. J Gravit Physiol 1999; 6: P47-P50.

107 Parker DE, Reschke MF, Arrott AP, Homick JL, Lichtenberg BK. Otolith tilt-translation reinterpretation following prolonged weightlessness: implications for preflight training. Aviat Space Environ Med 1985; 56: 601-606.

108 Ost MC, Lee BR. Urolithiasis in patients with spinal cord injuries: risk factors, management, and outcomes. Curr Opin Urol 2006; 16: 93-99.

109 Favazza T, Midha M, Martin J, Grob BM. Factors influencing bladder stone formation in patients with spinal cord injury. J Spinal Cord Med 2004; 27: 252-254.

110 DeVivo MJ, Fine PR, Cutter GR, Maetz HM. The risk of renal calculi in spinal cord injury patients. J Urol 1984; 131: 857-860.

111 Whitson PA, Pietrzyk RA, Morukov BV, Sams CF. The risk of renal stone formation during and after long duration space flight. Nephron 2001; 89: 264-270.

112 Whitson PA, Pietrzyk RA, Sams CF. Urine volume and its effects on renal stone risk in astronauts. Aviat Space Environ Med 2001; 72: 368-372.

113 Smith SM, Wastney ME, Morukov BV, Larina IM, Nyquist LE, Abrams SA et al. Calcium metabolism before, during, and after a 3-mo spaceflight: kinetic and biochemical changes. Am J Physiol 1999; 277: R1-R10.

114 Viroslav J, Rosenblatt R, Tomazevic SM. Respiratory management, survival, and quality of life for high-level traumatic tetraplegics. Respir Care Clin N Am 1996; 2: 313-322.

115 Campagnolo DI, Dixon D, Schwartz J, Bartlett JA, Keller SE. Altered innate immunity following spinal cord injury. Spinal Cord 2008; 46: 477-481.

116 Cruse JM, Keith JC, Bryant Jr ML, Lewis Jr RE. Immune systemneuroendocrine dysregulation in spinal cord injury. Immunol Res 1996; 15: 306-314.

117 Edgerton VR, Kim SJ, Ichiyama RM, Gerasimenko YP, Roy RR. Rehabilitative therapies after spinal cord injury. J Neurotrauma 2006; 23: 560-570.

118 de Castro MC, Cliquet Jr A. Artificial sensorimotor integration in spinal cord injured subjects through neuromuscular and electrotactile stimulation. Artif Organs 2000; 24: 710-717.

119 Fitts RH, Riley DR, Widrick JJ. Physiology of a microgravity environment invited review: microgravity and skeletal muscle. $J$ Appl Physiol 2000; 89: 823-839.

120 Mills PJ, Meck JV, Waters WW, D'Aunno D, Ziegler MG. Peripheral leukocyte subpopulations and catecholamine levels in astronauts as a function of mission duration. Psychosom Med 2001; 63: 886-890. 